\title{
BMJ Open The prognostic significance of smoking cessation after acute coronary syndromes: an observational, multicentre study from the Melbourne interventional group registry
}

Matias B Yudi, ${ }^{1,2}$ Omar Farouque, ${ }^{1,2}$ Nick Andrianopoulos, ${ }^{3}$ Andrew E Ajani, ${ }^{2,3,4}$ Katie Kalten, ${ }^{1}$ Angela L Brennan, ${ }^{3}$ Jeffrey Lefkovits, ${ }^{3,4}$ Chin Hiew, ${ }^{5}$ Ernesto Oqueli, ${ }^{6}$ Christopher M Reid, ${ }^{3,7}$ Stephen J Duffy, ${ }^{3,8}$ David J Clark, ${ }^{1,2}$ on behalf of the Melbourne Interventional Group

To cite: Yudi MB, Farouque 0 , Andrianopoulos $\mathrm{N}$, et al. The prognostic significance of smoking cessation after acute coronary syndromes: an observational, multicentre study from the Melbourne interventional group registry. BMJ Open 2017;7:e016874. doi:10.1136/ bmjopen-2017-016874

- Prepublication history for this paper is available online. To view these files, please visit the journal online (http://dx.doi. org/10.1136/bmjopen-2017016874).

Received 17 March 2017 Revised 31 August 2017 Accepted 1 September 2017

CrossMark

For numbered affiliations see end of article.

Correspondence to

Dr Matias B Yudi;

matiasyudi@gmail.com

\section{ABSTRACT}

Objective We aim to ascertain the prognostic significance of persistent smoking and smoking cessation after an acute coronary syndrome (ACS) in the era of percutaneous coronary intervention (PCI) and optimal secondary prevention pharmacotherapy.

Methods Consecutive patients from the Melbourne Interventional Group registry (2005-2013) who were alive at 30 days post-ACS presentation were included in our observational cohort study. Patients were divided into four categories based on their smoking status: non-smoker; exsmoker (quit >1 month before ACS); recent quitter (smoker at presentation but quit by 30 days) and persistent smoker (smoker at presentation and at 30 days). The primary endpoint was survival ascertained through the Australian National Death Index linkage. A Cox-proportional hazards model was used to estimate the adjusted $\mathrm{HR}$ and $95 \% \mathrm{Cl}$ for survival.

Results Of the 9375 patients included, 2728 (29.1\%) never smoked, 3712 (39.6\%) were ex-smokers, 1612 (17.2\%) were recent quitters and 1323 (14.1\%) were persistent smokers. Cox-proportional hazard modelling revealed, compared with those who had never smoked, that persistent smoking (HR 1.78, 95\% $\mathrm{Cl} 1.36$ to 2.32 , $p<0.001$ ) was an independent predictor of increased hazard (mean follow-up 3.9 \pm 2.2 years) while being a recent quitter ( $\mathrm{HR} 1.27,95 \% \mathrm{Cl} 0.96$ to $1.68, \mathrm{p}=0.10$ ) or an ex-smoker (HR 1.03, $95 \% \mathrm{Cl} 0.87$ to $1.22, \mathrm{p}=0.72$ ) were not.

Conclusions In a contemporary cohort of patients with ACS, those who continued to smoke had an $80 \%$ risk of lower survival while those who quit had comparable survival to lifelong non-smokers. This underscores the importance of smoking cessation in secondary prevention despite the improvement in management of ACS with $\mathrm{PCI}$ and pharmacotherapy.

\section{BACKGROUND}

Smoking is a well-recognised risk factor for coronary heart disease and accounts

\section{Strengths and Limitations of this study}

- The main strength of this study is the assessment of smoking cessation in a large contemporary population who were treated with percutaneous coronary intervention and optimal medical therapy, something which has not previously been explored.

- By using long-term mortality as the primary endpoint, we are able to assess the hazard of persistent smoking and benefit of smoking cessation after an acute coronary syndrome

- Patients' smoking habits can change over time, and thus our study is limited by the assessment of smoking status at only one time point.

for $11 \%$ of cardiovascular deaths worldwide. ${ }^{1}$ Smoking cessation has been consistently associated with a mortality benefit in both stable coronary artery disease and postacute coronary syndromes (ACS). ${ }^{2-4}$ Consequently, smoking cessation is one of the cornerstones of secondary prevention. ${ }^{5}$

However, the hazard of persistent smoking post-ACS in contemporary cardiology has not been described. Systematic reviews and meta-analysis have predominantly included studies from the prepercutaneous coronary intervention era. ${ }^{2-4}$ More recent studies assessing the impact of smoking post-ACS have focused primarily on younger $(<35 \text { years })^{6}$ or older populations ( $>65$ years), ${ }^{7}$ have had low rates of revascularisation, ${ }^{6-9}$ had suboptimal medical management ${ }^{10}$ or did not assess the impact of smoking cessation. ${ }^{711} 12$

Thus we aimed to assess the impact of persistent smoking or cessation at 30 days post ACS, compared with non-smokers, 
on survival in patients treated with percutaneous coronary intervention (PCI) and optimal secondary prevention pharmacotherapy.

\section{METHODS}

The study cohort included consecutive patients enrolled in the Melbourne Interventional Group (MIG) registry who underwent their index PCI for management of ACS between January 2005 and November 2013.

The MIG registry is a multicentre PCI registry and has been previously described in detail. ${ }^{13}$ Briefly, demographic, clinical, procedural and in-hospital outcome data are prospectively recorded on case report forms using standardised definitions for all fields with follow-up performed at 30 days and 12 months. ${ }^{14}$

The registry is coordinated by the Centre of Cardiovascular Research and Education in Therapeutics, an independent research body within the School of Public Health and Preventive Medicine at Monash University (Melbourne, Australia). An audit of a number of verifiable fields from $5 \%$ of randomly selected procedures at each institution is undertaken periodically. ${ }^{15}$ In the most recent audit, 27 fields were assessed with data accuracy of $98 \%$. This compares favourably to audits from other large registries. ${ }^{16}$ The ethics committee in each participating hospital has approved the MIG registry, including the use of 'opt-out' consent. This means that consent is presumed unless the patient 'opts out' after receiving a 'Patient Information Sheet'. If a patient informs a staff member that they do not wish to participate, the patient's data are not collected.

Patients who underwent PCI for ACS and survived to 30 days were included. ACS encompasses the spectrum of ST-elevation myocardial infarction (STEMI), non-ST-elevation myocardial infarction (NSTEMI) and unstable angina. STEMI was defined as ECG changes (new ST-segment elevation at the J-point or development of Q-waves in two or more contiguous leads) with confirmed myocardial necrosis (elevation in troponin $\mathrm{T}$ or I or creatine kinase-MB on at least one occasion within 24 hours from the index event). NSTEMI was defined as biomarker elevation consistent with myocardial necrosis and one of: either ST-segment depression or T-wave abnormality on ECG or ischaemic symptoms. Unstable angina is defined by clinical history suggestive of progressive, unstable ischaemic symptoms without cardiac biomarker elevation.

Acute management of all patients including interventional strategy, stent selection and antithrombotic therapy were left at the discretion of the operator in all procedures. Optimal secondary prevention pharmacotherapy was encouraged according to guidelines. No records were made of contraindications to medications or decisions regarding use/omission of particular guideline-directed therapies.

Patients were divided into four groups based on their smoking status at 30 days. Those who never smoked tobacco were included in the non-smoker group. Those who had quit smoking more than 1 month prior to ACS were classified as ex-smokers. Recent quitters were smokers at baseline but had quit by 30 days. Persistent smokers were smokers at baseline and were still smoking 30 days post-ACS.

The primary outcome was subsequent survival in those patients who were alive at 30 days post-ACS. Survival status was obtained by linkage to the Australian National Death Index (NDI). The Australian NDI is a database housed at the Australian Institute of Health and Welfare, which contains records of all deaths occurring in Australia since 1980. Data are obtained from the registries of births, deaths and marriages in each state and territory. The following variables for each deceased patient were identified: name, date of birth (or estimated year of birth), age at death, gender, date of death, state/territory of registration and registration number. Successful matching of patients through this linkage process was achieved in $99.4 \%$ of patients in the MIG registry.

Secondary outcomes were 12-month mortality, MI, stroke and major adverse cardiovascular events (MACCE). Twelve-month MACCE was defined as the combination of mortality, MI, stroke and target vessel revascularisation. MI was defined as an increase in CK or CK-MB $\geq 3$ times the upper limit of normal and/or a significant ST-segment change, development of new $Q$ waves in $\geq 2$ contiguous electrocardiographic leads or new left branch bundle block pattern in the context of new clinical symptoms.

\section{Statistical analysis}

Continuous variables are expressed as mean $\pm \mathrm{SD}$, and categorical data are expressed as numbers/percentages. Continuous variables were compared using Kruskal-Wallis equality-of-populations rank test. Categorical variables were compared using Fisher's exact or Pearson's $\chi^{2}$ tests as appropriate. Variables were tested for linear trends across the years 2005-2013 using Stata's nptrend command. This is a non-parametric test for trend across ordered groups that is an extension of the Wilcoxon rank-sum test. Cumulative incidence of mortality was estimated by the Kaplan-Meier method and the log-rank test was used to evaluate differences between groups. Cox-proportional hazards regression was used to estimate the adjusted HR and $95 \%$ CI for survival. Univariate variables with $\mathrm{p}<0.10$ were included for stepwise removal for the final multivariate model. The variables considered were: smoking status, age, sex, estimatedglomerular filtration rate, hypertension, diabetes, hypercholesterolaemia, family history of coronary disease, previous MI, previous PCI, previous coronaryartery bypass graft surgery (CABG), heart failure, peripheral vascular disease, cerebrovascular disease, left ventricular ejection fraction, multivessel $\mathrm{CAD}$, angina type, chronic lung disease, cardiogenic shock, glycoprotein IIb/IIIa use, drug-eluting stent use and treated left main lesion. 


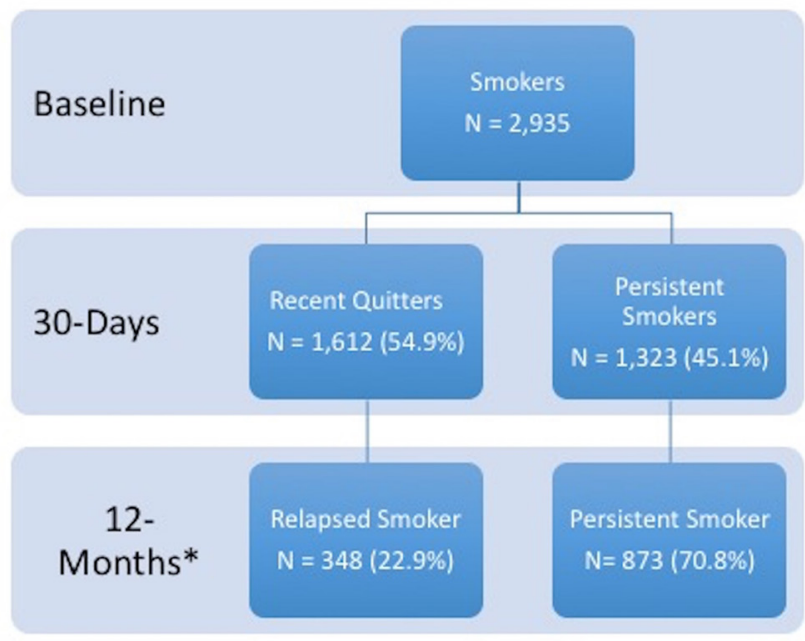

Figure 1 Smokers at baseline, 30 days and 12 months. *Includes only those patients alive at 12 months. Recent quitters were smokers at baseline but had quit by 30 days. Persistent smokers were smokers at baseline and were still smoking 30 days and 12 months post acute coronary syndrome. Relapsed smokers were smoking at 12 months although they temporarily quit at 30 days.

All statistical analyses were performed using Stata V.13.1 (StataCorp). p Values $<0.05$ were considered to be statistically significant.

\section{RESULTS}

Of the 9375 survivors following PCI for ACS at 30 days, $2728(29.1 \%)$ had never smoked, $3712(39.6 \%)$ were ex-smokers, $1612(17.2 \%)$ were recent quitters (smokers at the time of ACS but quit by 30 days) and 1323 (14.1\%) were persistent smokers. The smoking cessation rate at 30 days post-ACS was $54.9 \%$. Of the patients alive at 12 months, $23 \%$ of quitters had relapsed and $71 \%$ of persistent smokers continued to smoke (figure 1).

\section{Trends in smoking status}

Figure 2 depicts the trends in smoking status over the 9-year period from 2005 to 2013 . The percentage of non-smokers presenting with ACS increased over the

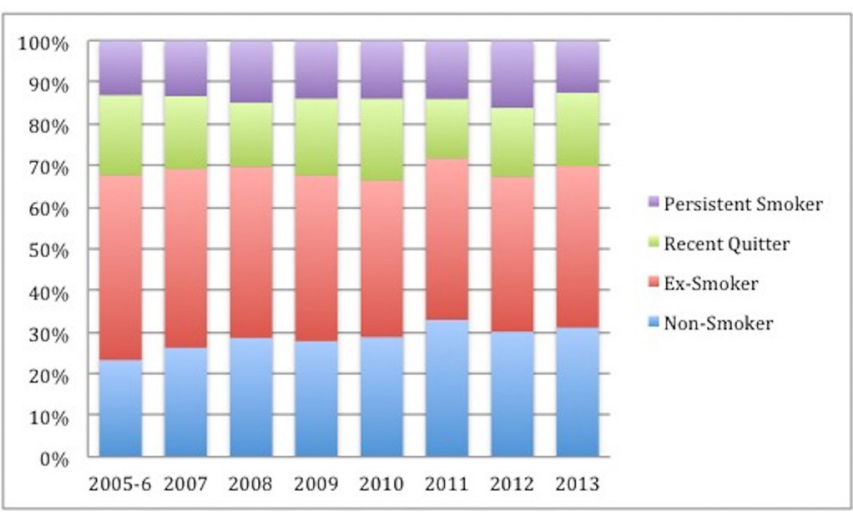

Figure 2 Trends in smoking status in acute coronary syndrome survivors at 30 days. time period while the rate of ex-smokers has decreased ( $p$ value for trend $=0.02$ ). There has been no significant change in the trend of smokers presenting with ACS.

\section{Clinical characteristics}

Baseline clinical characteristics stratified by smoking status at 30 days are shown in table 1 . It is evident smokers at the time of ACS (subsequent quitters and persistent smokers) were younger, had less comorbidities but a higher rate of a family history of premature CAD. Compared with quitters, persistent smokers were more likely to have had previously documented CAD (high rates of previous MI/ $\mathrm{PCI} / \mathrm{CABG}$ ), peripheral vascular disease and stroke.

ACS presentation type, angiographic characteristics and acute outcomes are shown in table 2. Smokers at time of ACS were more likely to present with STEMI, have single vessel CAD and receive a bare metal stent. They also had earlier discharge from hospital. The use of secondary prevention pharmacotherapy across all groups is depicted in table 3 .

\section{Clinical outcomes}

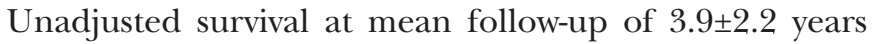
showed quitters had lower death rates than persistent smokers, non-smokers or ex-smokers $(5.3 \%$ vs $8.2 \%$ vs $9.6 \%$ vs $12.1 \%$, respectively; $\mathrm{p}<0.001)$. The full details of 12-month clinical outcomes and survival are shown in table 4. On multivariate analysis being an ex-smoker (HR $1.03,95 \% \mathrm{CI} 0.87$ to 1.22 ) or a quitter (HR $1.27,95 \% \mathrm{CI}$ 0.96 to 1.67 ) was not associated with an increased hazard compared with non-smokers but being a persistent smoker was associated with increased hazard (HR 1.78, $95 \%$ CI 1.36 to 2.32) (table 5 and figure 3). There was no evidence of any violation of the proportional hazards assumption as based on Schoenfeld residuals with a global test of $\chi^{2}=8.34$ with $14 \mathrm{df}, \mathrm{p}=0.784$.

\section{DISCUSSION}

In a contemporary cohort of patients presenting with ACS and treated with PCI and optimal secondary prevention pharmacotherapy, only $54 \%$ of patients stopped smoking by 30 days. Persistent smokers at 30 days post-PCI experienced an almost twofold increase in long-term mortality. Patients who quit smoking had a survival rate at 4 years that was similar to that of a lifelong non-smoker.

Cigarette smoking is a well-established cardiovascular risk factor and continues to be a major preventable cause of death. Ezzati et al estimated 11\% (1.62 million) of all global cardiovascular deaths in 2000 were attributable to smoking. ${ }^{1}$ Although the prevalence of smoking in the general population has decreased over the past 50 years in the USA, in our study the proportion of current smokers at time of ACS did not change significantly over 9 years. ${ }^{17}$ This emphasises the malignant pathophysiological effects of smoking, namely endothelial dysfunction, thrombogenicity and 
Table 1 Baseline clinical characteristics N (\%) stratified by smoking status at 30 days

\begin{tabular}{|c|c|c|c|c|c|}
\hline & $\begin{array}{l}\text { Non-smoker } \\
(n=2728)\end{array}$ & $\begin{array}{l}\text { Ex-smoker } \\
(n=3712)\end{array}$ & $\begin{array}{l}\text { Recent } \\
\text { quitter } \\
\text { ( } n=1612)\end{array}$ & $\begin{array}{l}\text { Persistent smoker } \\
(n=1323)\end{array}$ & p Value \\
\hline Age (mean \pm SD years) & $67.0 \pm 12.3$ & $67.0 \pm 11.5$ & $56.1 \pm 10.2$ & $56.7 \pm 10.6$ & $<0.001$ \\
\hline Age $>75$ years & $857(31.4)$ & $1093(29.5)$ & $74(4.6)$ & $82(6.2)$ & $<0.001$ \\
\hline Male & $1753(64.3)$ & $3038(81.8)$ & $1310(81.3)$ & $1028(77.7)$ & $<0.001$ \\
\hline $\mathrm{BMI}\left(\mathrm{mean} \pm \mathrm{SD} \mathrm{kg} / \mathrm{m}^{2}\right)$ & $28.0 \pm 5.3$ & $28.4 \pm 5.1$ & $28.4 \pm 5.3$ & $28.2 \pm 5.6$ & 0.004 \\
\hline Hypertension & $1738(63.7)$ & $2628(70.8)$ & $752(46.7)$ & 701 (53.0) & $<0.001$ \\
\hline Hypercholesterolaemia & 1665 (61.1) & $2627(70.8)$ & $895(55.6)$ & $806(61.1)$ & $<0.001$ \\
\hline Diabetes mellitus & $630(23.1)$ & $1014(27.3)$ & $216(13.4)$ & $244(18.4)$ & $<0.001$ \\
\hline Family history of CAD & 964 (35.5) & $1412(38.3)$ & $704(44.1)$ & $554(42.2)$ & $<0.001$ \\
\hline Previous MI & $444(16.3)$ & $1043(28.1)$ & $183(11.4)$ & $249(18.8)$ & $<0.001$ \\
\hline Previous $\mathrm{PCl}$ & 445 (16.3) & $884(23.8)$ & $168(10.4)$ & $222(16.8)$ & $<0.001$ \\
\hline Previous CABG & 159 (5.8) & $378(10.2)$ & $29(1.8)$ & $43(3.3)$ & $<0.001$ \\
\hline Congestive heart failure & $83(3.0)$ & $167(4.5)$ & $12(0.8)$ & $30(2.3)$ & $<0.001$ \\
\hline PVD & $92(3.4)$ & $313(8.4)$ & $55(3.4)$ & $83(6.3)$ & $<0.001$ \\
\hline Stroke & $157(5.8)$ & $293(7.9)$ & $46(2.9)$ & $61(4.6)$ & $<0.001$ \\
\hline Chronic lung disease & $166(6.1)$ & $516(13.9)$ & $118(7.3)$ & 170 (12.9) & $<0.001$ \\
\hline eGFR $\geq 60 \mathrm{~mL} / \mathrm{min} / 1.73 \mathrm{~m}^{2}$ & $1970(74.3)$ & $2726(74.9)$ & $1384(89.4)$ & 1135 (88.9) & $<0.001$ \\
\hline Ejection fraction $>45 \%$ & $1791(72.2)$ & $2311(70.5)$ & 1077 (71.9) & $846(70.6)$ & 0.61 \\
\hline
\end{tabular}

$\mathrm{BMI}$, body mass index; CABG, coronary artery bypass graft surgery; CAD, coronary artery disease; eGFR, estimated glomerular filtration rate; $\mathrm{MI}$, myocardial infarction; $\mathrm{PCl}$, percutaneous coronary intervention; PVD, peripheral vascular disease.

coronary vasoconstriction, which predispose patients to ACS events. ${ }^{18}$ Indeed, the significant role of smoking in the pathogenesis of ACS is further highlighted by the fact smokers were younger and lower rates of diabetes, hypertension and hypercholesterolaemia.
Smoking cessation is difficult, even after life-threatening events such as acute coronary syndromes. Systematic reviews have reported smoking cessation rates averaging around $50 \%$ in patients with coronary heart disease; this is consistent with the rates observed in our

Table 2 ACS presentation, angiographic characteristics and acute outcomes $\mathrm{N}(\%)$ by smoking status at 30 days

\begin{tabular}{|c|c|c|c|c|c|}
\hline & $\begin{array}{l}\text { Non-smoker } \\
(n=2728)\end{array}$ & $\begin{array}{l}\text { Ex-smoker } \\
(n=3712)\end{array}$ & $\begin{array}{l}\text { Recent } \\
\text { quitter } \\
\text { (n=1612) }\end{array}$ & $\begin{array}{l}\text { Persistent } \\
\text { smoker }(n=1323)\end{array}$ & p Value \\
\hline STEMI & $1243(45.6)$ & $1430(38.5)$ & $971(60.2)$ & $615(46.5)$ & \\
\hline NSTEMI & $1100(40.3)$ & $1591(42.9)$ & 547 (33.9) & $559(42.3)$ & \\
\hline Unstable angina & $385(14.1)$ & $691(18.6)$ & $94(5.8)$ & $149(11.3)$ & $<0.001$ \\
\hline Multivessel CAD & $1507(55.3)$ & $2291(61.8)$ & $806(50.2)$ & $655(49.7)$ & $<0.001$ \\
\hline Left main disease & $21(0.8)$ & $55(1.5)$ & $3(0.2)$ & $4(0.3)$ & $<0.001$ \\
\hline Balloon angioplasty only & $162(5.9)$ & $236(6.4)$ & $66(4.1)$ & $50(3.8)$ & $<0.001$ \\
\hline Bare metal stent & $1356(49.7)$ & $1949(52.5)$ & $918(57.0)$ & $781(59.0)$ & \\
\hline Drug eluting stent & $1210(44.4)$ & $1527(41.1)$ & $628(39.0)$ & $492(37.2)$ & $<0.001$ \\
\hline $\begin{array}{l}\text { Number of stents inserted } \\
\text { (mean } \pm \text { SD) }\end{array}$ & $1.2 \pm 0.6$ & $1.2 \pm 0.6$ & $1.2 \pm 0.6$ & $1.2 \pm 0.6$ & 0.44 \\
\hline Successful PCl & $2728(100)$ & $3711(100)$ & $1612(100)$ & $1322(99.9)$ & 0.42 \\
\hline New renal impairment & $34(1.3)$ & $35(0.9)$ & $10(0.6)$ & $4(0.3)$ & 0.01 \\
\hline New heart failure & $130(4.8)$ & $151(4.1)$ & $53(3.3)$ & $26(2.0)$ & $<0.001$ \\
\hline Length of stay (mean \pm SD days) & $5.2 \pm 5.2$ & $5.2 \pm 5.5$ & $4.5 \pm 4.1$ & $4.1 \pm 3.4$ & $<0.001$ \\
\hline
\end{tabular}

ACS, acute coronary syndrome; CAD, coronary artery disease; NSTEMI, non-ST-segment elevation myocardial infarction;

$\mathrm{PCl}$, percutaneous coronary intervention; STEMI, ST segment elevation myocardial infarction. 
Table 3 Cardiovascular pharmacotherapy N (\%) at 30 days by smoking status at 30 days

\begin{tabular}{lllllc}
\hline & $\begin{array}{l}\text { Non-smoker } \\
(\mathbf{n = 2 7 2 8 )}\end{array}$ & $\begin{array}{l}\text { Ex-smoker } \\
(\mathbf{n = 3 7 1 2})\end{array}$ & $\begin{array}{l}\text { Recent } \\
\text { quitter } \\
(\mathbf{n = 1 6 1 2})\end{array}$ & $\begin{array}{l}\text { Persistent smoker } \\
(\mathbf{n = 1 3 2 3})\end{array}$ & p Value \\
\hline Aspirin & $2665(97.7)$ & $3620(97.5)$ & $1593(98.8)$ & $1299(98.2)$ & 0.02 \\
\hline P2Y12 inhibitor & $2409(88.3)$ & $3301(88.9)$ & $1423(88.3)$ & $1204(91.0)$ & 0.06 \\
\hline Statin & $2610(95.7)$ & $3523(94.9)$ & $1583(98.2)$ & $1279(96.7)$ & $<0.001$ \\
\hline Beta-blocker & $2328(85.3)$ & $3019(81.3)$ & $1380(85.6)$ & $1120(84.7)$ & $<0.001$ \\
\hline ACE-I/ARB & $2313(84.8)$ & $3105(83.7)$ & $1381(85.7)$ & $1070(80.9)$ & 0.002 \\
\hline Warfarin & $259(9.5)$ & $295(8.0)$ & $111(6.9)$ & $84(6.4)$ & 0.001 \\
\hline Spironolactone & $66(2.4)$ & $96(2.6)$ & $11(0.7)$ & $29(2.2)$ & $<0.001$ \\
\hline Eplerenone & $60(2.2)$ & $67(1.8)$ & $38(2.4)$ & $30(2.3)$ & 0.49 \\
\hline Ezetimibe & $82(3.0)$ & $219(5.9)$ & $34(2.1)$ & $32(2.4)$ & $<0.001$ \\
\hline Fibrate & $27(1.0)$ & $62(1.7)$ & $16(1.0)$ & $20(1.5)$ & 0.06 \\
\hline
\end{tabular}

ACE-I, ACE inhibitor; ARB, angiotensin receptor blocker.

study. ${ }^{2-4}$ In addition, we found $23 \%$ of those who quit smoking at 30 days had relapsed at 12 months highlighting the difficulty of long-term abstinence. The severity of presentation may be a strong trigger to quit as a smoking cessation rate of $74 \%$ was reported in one study with STEMI patients alone. ${ }^{10}$ We also observed this in our study as patients presenting with STEMI were more likely to quit compared with those presenting with NSTEMI or unstable angina. Implementation of smoking cessation strategies is crucial and the index hospitalisation provides a perfect opportunity for this. Indeed a Cochrane review showed that smoking cessation rates were higher if counselling and pharmacotherapy were initiated during hospital admission. ${ }^{19}$

The 'smoker's paradox' in patients with acute coronary syndromes suggests there could be potential survival benefit seen in smokers. ${ }^{20}$ In our study, smokers had lower unadjusted mortality rates at 12 months and long term. However, when accounting for baseline differences in age and comorbidities, smoking status was no longer associated with improved survival, thus suggesting debunking of the 'smoker's paradox'. This is supported by a systematic review showing only studies in the prethrombolytic and thrombolytic era supporting the paradox, while none of the contemporary studies do. ${ }^{20}$

The cardiovascular risk associated with smoking appears to dissipate within 3 years of cessation. ${ }^{21} 22$ Systematic reviews have shown smoking cessation to be associated with a $35 \%$ relative risk reduction in patients with coronary heart disease and up to $46 \%$ in those with an MI. ${ }^{2-4}$ A limitation of these reviews is the inclusion of a significant proportion of patients from an era preceding percutaneous coronary intervention and optimal secondary prevention pharmacotherapy. More recent studies assessing the impact of smoking status following ACS have had suboptimal rates of revascularisation or medical management. ${ }^{6-10}$ Other studies did not assess the hazard of persistent smoking. ${ }^{7} 11 \quad 12$ In our study, persistent smoking after ACS was associated with an increased relative mortality risk of $78 \%$ at 4 years. The mortality hazard in our study was lower than the one described in a study of STEMI patients by Kinjo et al (HR 1.78 vs $2.27)$. Although their revascularisation rate was high $(>85 \%)$, only $30 \%$ of patients received statin therapy. Thus, it could be hypothesised that our higher rate of statin therapy may be responsible for our lower

Table 4 Clinical outcomes N(\%) by smoking status at 30 days

\begin{tabular}{lccccc}
\hline & $\begin{array}{l}\text { Non-smoker } \\
(\mathbf{n = 2 7 2 8 )}\end{array}$ & $\begin{array}{l}\text { Ex-smoker } \\
(\mathbf{n = 3 7 1 2})\end{array}$ & $\begin{array}{l}\text { Recent } \\
\text { quitter } \\
(\mathbf{n = 1 6 1 2})\end{array}$ & $\begin{array}{l}\text { Persistent smoker } \\
(\mathbf{n = 1 3 2 3})\end{array}$ & p Value \\
\hline Long-term mortality & $262(9.6)$ & $450(12.1)$ & $86(5.3)$ & $108(8.2)$ & $<0.001$ \\
\hline 12 month mortality & $50(1.9)$ & $100(2.8)$ & $13(0.9)$ & $18(1.4)$ & $<0.001$ \\
\hline 12 month MI & $122(4.7)$ & $222(6.2)$ & $51(3.3)$ & $56(4.5)$ & $<0.001$ \\
\hline 12 month stroke & $28(1.1)$ & $37(1.0)$ & $9(0.6)$ & $9(0.7)$ & 0.3 \\
\hline 12 month TVR & $182(7.0)$ & $272(7.6)$ & $118(7.7)$ & $65(5.2)$ & 0.03 \\
\hline 12 month MACCE & $309(11.9)$ & $488(13.7)$ & $157(10.2)$ & $117(9.3)$ & $<0.001$ \\
\hline
\end{tabular}

MACCE, major adverse cardiovascular events; MI, myocardial infarction; TVR, target vessel revascularisation. 
Table 5 Estimates of $\mathrm{HR}$ and $95 \% \mathrm{Cl}$ of predictors of longterm mortality using Cox-proportional hazards analysis

\begin{tabular}{lllc}
\hline & HR & $\mathbf{9 5 \%} \mathbf{C l}$ & p Value \\
\hline Unadjusted & & & \\
Non-smoker & Reference & - & - \\
Ex-smoker & 1.21 & 1.03 to 1.40 & 0.02 \\
Recent quitter & 0.51 & 0.40 to 0.65 & $<0.001$ \\
Persistent smoker & 0.82 & 0.65 to 1.03 & 0.08
\end{tabular}

Multivariate

analysis

\begin{tabular}{|c|c|c|c|}
\hline Non-smoker & Reference & - & - \\
\hline Ex-smoker & 1.03 & 0.87 to 1.22 & 0.72 \\
\hline Quitter & 1.27 & 0.96 to 1.68 & 0.10 \\
\hline Persistent smoker & 1.78 & 1.36 to 2.32 & $<0.001$ \\
\hline Age (per year) & 1.07 & 1.06 to 1.08 & $<0.001$ \\
\hline Multivessel CAD & 1.43 & 1.21 to 1.69 & $<0.001$ \\
\hline Drug-eluting stent & 0.78 & 0.67 to 0.92 & 0.002 \\
\hline $\begin{array}{l}\text { eGFR } \geq 60 \mathrm{~mL} / \\
\mathrm{min} / 1.73 \mathrm{~m}^{2}\end{array}$ & Reference & - & - \\
\hline $\begin{array}{l}\text { eGFR } 30-59 \mathrm{~mL} / \\
\mathrm{min} / 1.73 \mathrm{~m}^{2}\end{array}$ & 1.47 & 1.24 to 1.73 & $<0.001$ \\
\hline $\begin{array}{l}\text { eGFR }<30 \mathrm{~mL} / \\
\mathrm{min} / 1.73 \mathrm{~m}^{2}\end{array}$ & 3.83 & 2.96 to 4.94 & $<0.001$ \\
\hline$E F>45 \%$ & Reference & - & - \\
\hline EF $30 \%-45 \%$ & 1.55 & 1.33 to 1.80 & $<0.001$ \\
\hline$E F<30 \%$ & 1.60 & 1.12 to 2.29 & 0.010 \\
\hline Diabetes mellitus & 1.51 & 1.29 to 1.77 & $<0.001$ \\
\hline Periprocedural MI & 1.33 & 1.13 to 1.56 & $<0.001$ \\
\hline $\begin{array}{l}\text { Peripheral vascular } \\
\text { disease }\end{array}$ & 1.65 & 1.35 to 2.02 & $<0.001$ \\
\hline Chronic lung disease & 1.73 & 1.44 to 2.08 & $<0.001$ \\
\hline
\end{tabular}

CAD, coronary artery disease; EF, ejection fraction; eGFR, estimated glomerular filtration rate; MI, myocardial infarction.

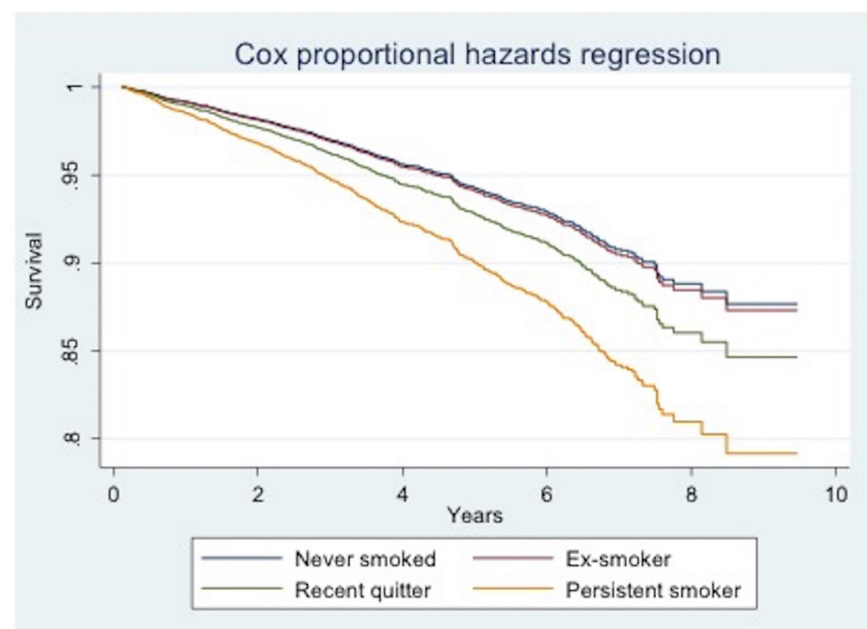

Figure 3 Cox proportional hazard regression survival curve. long-term mortality risk. What is unquestionable, as observed in our study, is that a substantial residual mortality risk remains in patients who persist with smoking despite optimal contemporary management with PCI and optimal secondary prevention pharmacotherapy. This increased risk is of similar magnitude to those seen from earlier cardiology eras. ${ }^{2-4}$

Encouragingly, smoking cessation is beneficial and by 4 years our cohort of quitters had a mortality hazard approaching that of lifelong non-smokers. This is theoretically plausible as the deleterious hazards of smoking appear to be reversed within this time frame and cardiac risk has been shown to return to baseline. ${ }^{182122}$ Although complete smoking abstinence is difficult, as previously discussed, Gerber et al showed that even a five-cigarette a day reduction is associated with an $18 \%$ decline in mortality. ${ }^{8}$ Again this highlights the importance of smoking cessation or even smoking reduction in secondary prevention.

Our study has a number of limitations. First, inherent to all studies assessing the impact of persistent smoking and cessation, the associations described in our study could be attributed, at least partly, to unaccounted or unmeasured variables. In particular, we did not account for the participation in cardiac rehabilitation programme or for smoking cessation strategies used. Second, we have measured smoking status at one time point and even at 12 months there were a significant number of patients who changed their smoking habits and thus were initially misclassified. We chose smoking cessation at 30 days to assess the impact of the admission with ACS and early medical intervention. Third, we ascertained smoking status by self-report. Although it has been shown to correlate with biochemical assessment in a meta-analysis, there is always a potential for misclassification. ${ }^{23}$ Fourth, we have only included ACS patients treated with PCI which limits the generalisability of our results to this patient population. Fifth, we included repeated admissions as separate cases which raises the possibility of multiple counting. Lastly, we do not collect a detailed smoking history and thus we could not quantify the mortality hazard based on the quantity of cigarettes smoked over a lifetime, nor could we quantify the benefit of cessation based on the time since the last cigarette was smoked. Future research should focus on collecting and analysing this data to more accurately quantify the effect of smoking post ACS.

\section{CONCLUSION}

Patients who continued to smoke after an ACS had a nearly twofold mortality hazard while those who quit had comparable survival to a non-smoker. This underscores the importance of smoking cessation in secondary prevention, despite the improvement in management of ACS with percutaneous coronary intervention and optimal medical therapy. 


\section{Author affiliations}

${ }^{1}$ Department of Cardiology, Austin Health, Melbourne, Victoria, Australia

${ }^{2}$ Department of Medicine, University of Melbourne, Melbourne, Australia

${ }^{3}$ Centre of Cardiovascular Research and Education in Therapeutics (CCRE), Monash

University, Melbourne, Australia

${ }^{4}$ Department of Cardiology, Royal Melbourne Hospital, Melbourne, Australia

${ }^{5}$ Department of Cardiology, Barwon Health, Geelong, Australia

${ }^{6}$ Department of Cardiology, Ballarat Base Hospital, Ballarat, Australia

${ }^{7}$ School of Public Health, Curtin University, Perth, Western Australia

${ }^{8}$ Department of Cardiovascular Medicine, Alfred Hospital, Melbourne, Australia

Acknowledgements The Melbourne Interventional Group acknowledges and thanks all patients who have been involved in the registry. Dr MBY is supported by a combined National Health and Medical Research Council Postgraduate Scholarship (APP 1115163) and a National Heart Foundation Health Professional Scholarship (Award ID 101130).

Contributors MY, OF and DC developed the project concept and research hypothesis. MY and DC drafted the manuscript. NA, AB and CR provided statistical support. OF, AA, KK, JL, CH, EO and SD critically revised the manuscript for intellectual content. All authors read and approved the final document.

Funding The Melbourne Interventional Group acknowledge sunrestricted educational grant funding from: Abbott Vascular, Astra-Zeneca,Medtronic, MSD, Pfizer, Servier and The Medicines Company. These companies do not have access to the data and do not have the right to review manuscripts before publication. Professor SJD \& Professor Reid's work is funded by National Health and Medical Research Council of Australia Grants.

Competing interests None declared.

Ethics approval The study was approved by all individual hospitals involved in the Melbourne Interventional Group.

Provenance and peer review Not commissioned; externally peer reviewed.

Data sharing statement № additional data are available.

Open Access This is an Open Access article distributed in accordance with the Creative Commons Attribution Non Commercial (CC BY-NC 4.0) license, which permits others to distribute, remix, adapt, build upon this work non-commercially, and license their derivative works on different terms, provided the original work is properly cited and the use is non-commercial. See: http://creativecommons.org/ licenses/by-nc/4.0/

(c) Article author(s) (or their employer(s) unless otherwise stated in the text of the article) 2017. All rights reserved. No commercial use is permitted unless otherwise expressly granted.

\section{REFERENCES}

1. Ezzati M, Henley SJ, Thun MJ, et al. Role of smoking in global and regional cardiovascular mortality. Circulation 2005;112:489-97.

2. Critchley JA, Capewell S. Mortality risk reduction associated with smoking cessation in patients with coronary heart disease: a systematic review. JAMA 2003;290:86-97.

3. Wilson K, Gibson N, Willan A, et al. Effect of smoking cessation on mortality after myocardial infarction: meta-analysis of cohort studies. Arch Intern Med 2000;160:939-44.

4. Van Berkel TF, Boersma H, Roos-Hesselink JW, et al. Impact of smoking cessation and smoking interventions in patients with coronary heart disease. Eur Heart J 1999;20:1773-82.
5. Smith SC, Benjamin EJ, Bonow RO, et al. AHA/ACCF secondary prevention and risk reduction therapy for patients with coronary and other atherosclerotic vascular disease: 2011 update: a guideline from the American Heart Association and American College of Cardiology Foundation endorsed by the World Heart Federation and the Preventive Cardiovascular Nurses Association. J Am Coll Cardiol 2011:58:2432-46.

6. Rallidis LS, Sakadakis EA, Tympas K, et al. The impact of smoking on long-term outcome of patients with premature ( $\leq 35$ years) ST-segment elevation acute myocardial infarction. Am Heart $J$ 2015;169:356-62.

7. Bucholz EM, Beckman AL, Kiefe Cl, et al. Smoking status and life expectancy after acute myocardial infarction in the elderly. Heart 2016;102:133-9.

8. Gerber Y, Rosen LJ, Goldbourt U, et al. Smoking status and longterm survival after first acute myocardial infarction a populationbased cohort study. J Am Coll Cardiol 2009;54:2382-7.

9. Shah AM, Pfeffer MA, Hartley LH, et al. Risk of all-cause mortality, recurrent myocardial infarction, and heart failure hospitalization associated with smoking status following myocardial infarction with left ventricular dysfunction. Am J Cardiol 2010;106:911-6.

10. Kinjo K, Sato H, Sakata Y, et al. Impact of smoking status on longterm mortality in patients with acute myocardial infarction. Circ $J$ 2005;69:7-12.

11. Weisz G, Cox DA, Garcia E, et al. Impact of smoking status on outcomes of primary coronary intervention for acute myocardial infarction-the smoker's paradox revisited. Am Heart $J$ 2005;150:358-64.

12. Shen L, Peterson ED, Li S, et al. The association between smoking and long-term outcomes after non-ST-segment elevation myocardial infarction in older patients. Am Heart J 2013;166:1056-62.

13. Ajani $A E$, Szto G, Duffy SJ, et al. The foundation and launch of the Melbourne Interventional Group: a collaborative interventional cardiology project. Heart Lung Circ 2006;15:44-7.

14. Chan W, Clark DJ, Ajani AE, et al. Progress towards a national cardiac procedure database-development of the Australasian Society of Cardiac and Thoracic Surgeons (ASCTS) and Melbourne Interventional Group (MIG) registries. Heart Lung Circ 2011;20:10-18.

15. Andrianopoulos N, Dinh D, Duffy SJ, et al. Quality control activities associated with registries in interventional cardiology and surgery. Heart Lung Circ 2011;20:180-6.

16. Lagerqvist B, James SK, Stenestrand U, et al. Long-term outcomes with drug-eluting stents versus bare-metal stents in Sweden. $N$ Engl $J$ Med 2007;356:1009-19.

17. Thun MJ, Carter BD, Feskanich D, et al. 50-year trends in smoking-related mortality in the United States. N Engl J Med 2013;368:351-64.

18. Ambrose JA, Barua RS. The pathophysiology of cigarette smoking and cardiovascular disease: an update. J Am Coll Cardiol 2004:43:1731-7.

19. Rigotti NA, Clair C, Munafò MR, et al. Interventions for smoking cessation in hospitalised patients. Cochrane Database Syst Rev 2012;5:CD001837.

20. Aune E, Røislien J, Mathisen M, et al. The "smoker's paradox" in patients with acute coronary syndrome: a systematic review. BMC Med 2011;9:97.

21. Rosenberg L, Palmer JR, Shapiro S. Decline in the risk of myocardial infarction among women who stop smoking. N Engl J Med 1990;322:213-7.

22. Rosenberg L, Kaufman DW, Helmrich SP, et al. The risk of myocardial infarction after quitting smoking in men under 55 years of age. $N$ Engl $J$ Med 1985;313:1511-4

23. Patrick DL, Cheadle A, Thompson DC, et al. The validity of selfreported smoking: a review and meta-analysis. Am J Public Health 1994;84:1086-93. 